\title{
Isolation and Mass Production of Entomopathogenic Nematode Steinernema saimkayai using Semi Solid Dog Feed Medium
}

\author{
Jissin Mathew (D), Vani C.* (iD) and Jaison Titus (iD) \\ Department of Biotechnology, Karunya Institute of Technology and Sciences, Coimbatore, India.
}

\begin{abstract}
Entomopathogenic nematodes (EPNs) were collected from soil using Galleria mellonella as bait and propagated on Wouts medium as well as new semi-solid feed developed from dog feed. The EPN was isolated from the cucumber soil from Kadayar, Thadiyoor, Kerala for the Mass production. The strains collected were identified as Steinernema siamkayai KUT1 and the symbiont bacteria identified as Xenorhabdus stockiae using advanced DNA sequencing method. Nematodes were grown on two different sets of medium viz., Wouts medium on sponge and Semi-solid dog feed in T-flasks. The Steinernema siamkayai KUT1 grown increasingly in semi-solid dog feed medium than other medium. This research suggests that EPN can be used to for the inhibition of malarial parasites in open stagnant water bodies. Breeding grounds for this species could be controlled efficiently using EPNs. Our research concludes the use of newly modified semi solid Dog feed medium containing essential nutrients can be safe and cheap enough for the mass production of EPN.
\end{abstract}

Keywords: Galleria mellonella, Entomopathogenic nematode, Mass production, Dog feed semi solid media

*Correspondence: vani@karunya.edu; 9842215562

(Received: May 06, 2019; accepted: February 05, 2020)

Citation: Jissin Mathew, Vani C. and Jaison Titus, Isolation and Mass Production of Entomopathogenic Nematode Steinernema saimkayai using Semi Solid Dog Feed Medium, J. Pure Appl. Microbiol., 2020; 14(1):499-507. https://doi.org/10.22207/ JPAM.14.1.52

(C) The Author(s) 2020. Open Access. This article is distributed under the terms of the Creative Commons Attribution 4.0 International License which permits unrestricted use, sharing, distribution, and reproduction in any medium, provided you give appropriate credit to the original author(s) and the source, provide a link to the Creative Commons license, and indicate if changes were made. 


\section{INTRODUCTION}

The word entomopathogenic has a Greek starting point entomon, alludes to insects, and pathogenic, which indicates bringing on ailment. They are multi-cell metazoans that possess a bio control center ground between microbial pathogens and predator/parasitoids, and are frequently assembled with pathogens. The Genera of the entomopathogenic nematodes such as Heterorhabditis and Steinernema are obligate parasites of insect pests (Gaugler 2006). The entomopathogenic nematodes are nonfragmented worms. The free living Infective Juveniles (IJs) enters the host hemolymph the nematode symbionts kills the insects within 24 to 48 hours. Thus the symbiont microorganism avail the nematodes to feed on the host tissue thereby the descendant nematodes develop and the lifecycle repeats (Kaya and Gaugler 1993). Entomopathogenic nematodes use two strategies: ambushers or cruisers (Grewal et al. 1994). Ambushers such as Steinernema carpocapsae adapt energy-conserving approach and lie-in-wait to attack mobile insects in the upper soil. Cruisers like Steinernema glaseri and Heterorhabditis bacteriophora are comparatively highly active and generally subterranean, moving particular distances using volatile cues and other methods to find their host underground. Therefore, they are effective against less mobile pests such as white grubs. Some nematode species such as Steinernema feltiae and Steinernema riobrave uses intermediate foraging strategy (ambush and cruiser type) to find their host.

The potential of the EPNs in the field has not been studied thoroughly, though some of the research has been carried out. Recently, studies have shown utilizing both EPNs (steinernematids and heterorhabditids) in combination for biological control of plum curculio in orchards in Northeast America have reduce populations by as much as $70-90 \%$ in the field, depending on insect stage, treatment timing and field conditions. Studies are being conducted for the efficacy of EPNs as a biological control agent for organic growers as an alternative solution to chemistries that aren't as effective at controlling insect infestations (Agnello et al. 2014). In India, the potential of this biocontrol agent for pests is less known. If this complex is used in large numbers many unwanted chemicals could be stopped from been sprayed onto the field which in turn leads to a healthy food chain. Mass production as well as awareness of EPNs in India is very much essential to halt the hazardous pesticides currently been used.

EPNs affect their host insects, thereby they can also change the species composition of the soil community. Aside from EPNs, the soil ecosystem includes predatory, bacteriovorous, fungivorous and plant parasitic nematode species. Since EPNs are applied in agricultural systems at a rate of $1,000,000$ individuals per acre, the potential for better yields of crops can be expected. Future research on the production of EPNs could invariably solve the problem of plant parasites and chemical pesticides been used on plants. The pest attack on important crops has devastating effects on the farmer as well as the consumer on the other end. To overcome this loss, the farmers used Chemical pesticides in large scale which leads to severe health problems for the population consuming it. In aboveground communities, but the application of EPNs have few side effects on other animals. One study reported that Steinernema felidae and Heterorhabditis megidis, when applied in a range of agricultural and natural habitats, had little impact on non-pest arthropods. Some minimal impacts did occur, however, on non-pest species of beetles and flies (Bathon 1996). Unlike chemical pesticides, EPNs are considered safe for humans and other vertebrates. Production of EPNs in mass number using a specifically designed bioreactor so as to produce high number of infective juveniles is more cost-effective than in vivo production for large scale purposes. The aim of the current study is to mass produce Entomopathogenic nematode using semi solid medium for biological control of insect pests.

\section{MATERIALS AND METHODS Rearing of Galleria mellonella}

Greater wax moth Galleria mellonella larvae were obtained from Sugarcane Breeding Institute, Tamil Nadu. The larvae were then reared on artificial diet containing following composition corn flour $-200 \mathrm{~g}$, milk powder $-130 \mathrm{~g}$, yeast $-70 \mathrm{~g}$, honey $-100 \mathrm{ml}$ and glycerin $-150 \mathrm{ml}$ for the mass production (Hala et al. 2018). 
Collection of Soil Samples for the Isolation of Entomopathogenic Nematode by Insect Baiting Technique

Ten different agricultural field soil samples such as Tomato, Ginger, Cucumber, Turmeric, Coconut, Banana, Yam, Tapioca, Sugar Cane and Pumpkin were collected from the depth of atleast $15 \mathrm{~cm}$. Visual debris were removed from the collected soil samples to avoid saprobic contamination. Approximately 200-250gm of moist samples were kept in clean closed container. To the 10 different soil sample container 5 count of Galleria mellonella larvae were inoculated for baiting with particular nematodes. The containers were covered with black cloth to aid the infection at $25-28^{\circ} \mathrm{C}$. The soil samples infected with Gallerial larvae were observed everyday for upto 7 days and the cadaver infected with the nematode appeared black color indicated the presence of Steinernema species were rinsed thoroughly in sterile water (Hala et al. 2018).

Surface Sterilization of Isolated Entomopathogenic Nematode using White Trap Method

Six $\mathrm{ml}$ of Nematode suspension were centrifuged at $1500 \mathrm{rpm}$ for $5 \mathrm{~min}$ and the supernatant were discarded. Then the pellets were resuspended in $0.1 \%$ bleach solution and gently inverted the suspension in tube for $7 \mathrm{~min}$ at room temperature using Bleach Treatment. A volume of $14 \mathrm{ml}$ of fresh water was added and centrifuged 4 times at $1500 \mathrm{rpm}$ for $5 \mathrm{~min}$ to discard all the bleach residues. After the centrifugation $1 X$ PBS buffer was suspended and the tubes were inverted around $5 \mathrm{~min}$ and were centrifuged at $1500 \mathrm{rpm}$ for $5 \mathrm{~min}$. Finally the isolated entomo-pathogenic nematodes were resuspended in sterile $0.85 \%$ $\mathrm{NaOCl}$ (Wouts 1981).

\section{Morphological characterization}

For morphological characterization of the isolate, nematodes were heat-killed in $60^{\circ} \mathrm{C}$ Ringer's solution. The heat-killed nematodes were placed in triethanolamin formalin (TAF) fixative and processed to anhydrous glycerine for mounting. The morphological features of males and IJs and hermaphroditic female were randomly selected from different $G$. mellonella under light microscopy according to procedures described by Seinhorst method (Seinhorst 1962). The identity was verified by comparing its morphometrics with the data from original descriptions.
Molecular characterisation, PCR amplification and sequencing

Molecular identification of the all EPN isolates was performed in order to confirm the results of the morphological identification. For DNA isolation, water suspensions containing 1000 $\mathrm{IJs} / \mathrm{ml}$ of each isolates reared on $\mathrm{G}$. melonella under laboratory conditions were used. For each isolate, one $\mathrm{ml}$ of suspension was transferred to an Eppendorf tube and centrifuged at $10000 \mathrm{rpm}$ for one minute. The resulting precipitate was homogenized with a pestle and mortar containing liquid nitrogen and the DNA was extracted using QIAGEN DNeasy Blood and Tissue Kit following the Bench Spin-Column Protocol for Animal Tissues. A modification was made to the two DNA elution steps in the instructions of the manufacturer, where, instead of $200 \mu \mathrm{l}$ of AE Buffer for each step, $50 \mu \mathrm{l}$ and $25 \mu \mathrm{l}$ were used respectively in order to obtain higher DNA concentrations. The resulting DNA extracts were used in PCR reactions with primers based on ITS/18SrDNA TW81 $=5^{\prime}$-GTTTCCGTAGGTGAACCTGC- ${ }^{\prime}$ and AB28 = 5'-ATATGCTTAAGTTCAGCGGGT-3' as described by Joyce et al. (1994). The PCR mix for one reaction contained $4 \mu$ l of PCR Taq buffer $10 \mathrm{x}, 2 \mu \mathrm{l}$ of $100 \mu \mathrm{M}$ dNTPs, $1.0 \mu \mathrm{l}$ of each primer, $1.0 \mu \mathrm{l} 2 \mathrm{U}$ Taq Polymerase, $5 \mu \mathrm{l}$ DNA extract and $\mathrm{ddH} 2 \mathrm{O}$ to a final volume of $40 \mu \mathrm{l}$. The PCR profile consisted of one cycle of $94^{\circ} \mathrm{C}-5 \mathrm{~min}$ followed by 35 cycles of $94^{\circ} \mathrm{C}-30 \mathrm{sec}, 55^{\circ} \mathrm{C}-45 \mathrm{sec}, 72^{\circ} \mathrm{C}-1.3$ min and a final extension at $72^{\circ} \mathrm{C}-5 \mathrm{~min}$. PCR was followed by electrophoresis ( $45 \mathrm{~min}, 120 \mathrm{~V}$ ) of PCR product in a $1 \%$ TAE buffered agarose gel stained with ethidium bromide. The PCR products were purified using QIAGEN QIAquick PCR Purification Kit in accordance with the instructions of the manufacturer and sent for sequencing to Bioserve (INDIA). The PCR purified products were sequenced and compared with those deposited in GenBank by means of a Basic Local Alignment Search Tool (BLAST) of the National Centre for Biotechnology Information (NCBI).

\section{Anexization of Nematode Eggs}

Surface sterilization still has major disadvantages as some bacterial non-symbiont species attaches to the cuticle of the Infective Juveniles. For the liquid media mass production anexization of eggs are beneficial. Gravid females of the Steinernema species were obtained from the invite method of 
Table 1. Occurrence of Entomopathogenic Nematodes in different soil sample from Chempakathinal $(\mathrm{H})$ Thadiyoor

\begin{tabular}{ll}
\hline $\begin{array}{l}\text { Samples Isolated from } \\
\text { Thadiyoor Agriculture Soils }\end{array}$ & $\begin{array}{c}\text { Steinernema } \\
\text { species }\end{array}$ \\
\hline Turmeric & Negative \\
Yam & Negative \\
Ginger & Negative \\
Banana & Negative \\
Cucumber & Positive \\
Tomato & Negative \\
Tapioca & Negative \\
Coconut & Negative \\
Sugarcane & Negative \\
Pumpkin & Negative \\
\hline
\end{tabular}

nematode production. The female nematodes were digested in $0.4 \mathrm{M} \mathrm{NaOH}$ axenizing solution for $15 \mathrm{~min}$ and were dissected to release the eggs. The eggs were transferred to Eppendorf tube. Eppendorf tube containing eggs were subjected for centrifugation at $5000 \mathrm{rpm}$ for $5 \mathrm{~min}$ and the supernatant was carefully removed. Further fresh $\mathrm{NaOH}$ was added and slowly inverted for $5 \mathrm{~min}$. The suspension was then centrifuged at $5000 \mathrm{rpm}$ for $5 \mathrm{~min}$ and the supernatant was discarded. To obtain clean nematode eggs, the tubes containing eggs were centrifuged twice at $1500 \mathrm{rpm}$ for $5 \mathrm{~min}$ at twice. To check the presence of contaminating microorganisms the eggs were streaked onto LA medium (Joyce et al. 1994).

In Vitro Propagation of Entomopathogenic Nematodes in Soild Media

Infective juveniles which were recovered from Galleria mellonella using white trap were used for artificial propagation in Erlenmeyer flasks. Wouts media were prepared with Hi Media Nutrient Broth $0.44 \mathrm{~g}$, Hi Media Yeast extract 0.16 g, Phalada Pure \& Sure Organic Soya flour 7.20 g, Groundnut oil $5.20 \mathrm{~g}$ were mixed in $27 \mathrm{~g}$ of distilled water (Wouts, 1981). Using a mortar and pestle the materials were thoroughly grinded to obtain a
Table 2. Morphometric characters of infective juveniles of S.siamkayai $(n=25)$ (Mean and Range, all measurements in $\mu \mathrm{m}$ )

\begin{tabular}{lccc}
\hline $\begin{array}{l}\text { Nematode } \\
\text { Isolates }\end{array}$ & $\begin{array}{c}\text { Length } \\
\text { (L) }\end{array}$ & $\begin{array}{c}\text { Excretory } \\
\text { pore (EP) }\end{array}$ & $\begin{array}{c}\text { Tail Length } \\
\text { (TL) }\end{array}$ \\
\hline $\begin{array}{l}\text { S. siamkayai } \\
\text { KUT1 }\end{array}$ & $\begin{array}{c}441 \\
(393-490)\end{array}$ & $\begin{array}{c}34 \\
(30-38)\end{array}$ & $\begin{array}{c}35 \\
(31-41)\end{array}$ \\
\hline
\end{tabular}

uniform solution. Light polyurethane foam was cut in cuboidal chips weighing, $1.5 \mathrm{~g}$ were soaked in the Wouts media and placed inside the flask. The flask was autoclaved at $121^{\circ} \mathrm{C}$ for $15 \mathrm{~min}$ and after cooling, an inoculum of $4.8 \times 10^{4}$ surface sterilized IJs were poured into the flask. The flask was kept below $25^{\circ} \mathrm{C}$ in a dark room.

\section{New Semi-Solid Dog-Feed in T-flask}

For the semi-solid feed, two different types of media were prepared, smashed media along with some additions and readily available media (dog-feed). The smashed media was divided into different concentrations with the addition of sterile distilled water. New type of dog feed which is readily available in the market as Pedigree Gravy Adult Chicken and Liver Chunks was used as food source for the nematodes and cultured in tissue culture flask. Dog feed contains crude protein (8\%), crude fat (4\%), crude fiber (3\%), moisture (85\%) and made of different ingredients including chicken, chicken by-products, minerals, dietary fiber, amino acid, vitamins, soya bean oil, gravy, and wheat gluten. Dog feed (8.5g) was poured into the T-25 flask (Nest) under sterile conditions. The inoculum size was approximately 7000 surface sterilized IJs was pipetted into the flasks and incubated below $25^{\circ} \mathrm{C}$ under dark (Wouts 1981).

\section{RESULTS}

\section{Rearing of Galleria mellonella and Immunization} of insects

The Galleria mellonella was allowed to

Table 3. The nematodes were harvested on the $20^{\text {th }}$ day from the date of inoculation from all the flasks

\begin{tabular}{lcccccc}
\hline Nematode Culture & \multicolumn{4}{c}{ Feed quantity } & \multicolumn{2}{c}{ Inoculum size } \\
\hline Semi Solid (Dog Feed & $\mathrm{T} 1$ & $\mathrm{~T} 2$ & $\mathrm{~T} 3$ & $\mathrm{~T} 4$ & $\mathrm{~T} 5$ & \\
medium and Sterile & $5 \mathrm{gm}+$ & $5 \mathrm{gm}+$ & $5 \mathrm{gm}+$ & $5 \mathrm{gm}+$ & $5 \mathrm{gm}+$ & $2.5 \times 106 \mathrm{JJ} /$ flask \\
$\begin{array}{l}\text { Distilled water) in } \\
\text { Tissue culture (T25) flask }\end{array}$ & $10 \mathrm{ml}$ & $10 \mathrm{ml}$ & $10 \mathrm{ml}$ & $10 \mathrm{ml}$ & $10 \mathrm{ml}$ & \\
\hline Journal of Pure and Applied Microbiology & & & & & \\
\hline
\end{tabular}


Table 4. Multiplication of Steinernema saimkayai in Dog feed medium

\begin{tabular}{ccccc}
\hline \multicolumn{5}{c}{ Nematode concentration per flask } \\
T1 & T2 & T3 & T4 & T5 \\
& & & & \\
\hline $7.8 \times 10^{6}$ & $6.1 \times 10^{6}$ & $5.5 \times 10^{6}$ & $5.0 \times 10^{6}$ & $4.1 \times 10^{6}$
\end{tabular}

rear and multiply on artificial diet for one week in dark conditions. The eggs layed from the wax moth (Galleria mellonella) were separated and placed onto another diet container. Approximately more than 500 eggs were layed and kept for hatching. The morphological characteristics of eggs were small, shiny, yellowish golden colour.

Collection of Soil Samples for The Isolation of Entomopathogenic Nematode by Insect Baiting Technique

Out of the 10 different agricultural field soil samples such as Tomato, Ginger, Cucumber, Turmeric, Coconut, Banana, Yam, Tapioca, Sugar Cane and Pumpkin, only 1 sample had the entomopathogenic nematodes (Table 1). On the $7^{\text {th }}$ day 5 larvae were dead from cucumber plantation soil. The dead black larvae were kept for white trap method and presence of entomopathogenic nematodes observed. EPNs sequencing results revealed 98\% match for Steinernema siamkayai KUT1 and the bacterial symbiont was identified as Xenorhabdus stockiae KUT6 Genbank Number MF521441 at 99\% match (Fig. 1, 2 and 3).

Surface Sterilization of Isolated Entomopathogenic Nematode using White Trap Method

The isolated Entomopathogenic nematodes were surface sterilized with $0.1 \%$ formaldehyde and removed all the contaminants. Morphological Characterization

The morphometric measurements of the male and IJs coincide well with the description given by Poinar et al. (1992). length of IJs was less than $600 \mu \mathrm{m}, 486 \mu \mathrm{m}$ in the present study, Head to excretory pore $35 \mu \mathrm{m}$ and Tail length $40 \mu \mathrm{m}$. The third stage of Juveniles is slender, tapering regularly from base of oesophagus to anterior end and from anus to terminus. Oesophagus is long, and narrow. The first generation of male curved posteriorly, J -shaped when heatkilled (Table 2). In vitro propagation in Solid Media

Solid in vitro propagation was carried out in Wouts media approximately 2.5 million IJs per flask were recovered and maintained. The nematodes can be seen visible over the surface of the conical flasks. The nematodes were harvested from the sponge using Baemann funnel technique and are then sealed and stored in BOD incubator at $13^{\circ} \mathrm{C}$.

In vitro propagation using semisolid media

In semisolid media containing dog food the Infective Juveniles have jolted to the next stage of growth after 15 hours of inoculation. They were cultured in T-flasks for initial experiments. The IJs were visible at the end of 2 weeks on walls of the flask and by the end of the $4^{\text {th }}$ week the nematodes were harvested. Around $2.5 \times 10^{6}$ IJs average of all the nematodes harvested per flasks.

The semi-solid media were checked for growth and instant growth was observed on nematodes from J3 to J4 stage, one day after inoculation. After 12 days the nematode concentration was approximately around 61,500 nematodes, with most of them in the $F_{2}$ generation adult stage (Fig. 4). Nematode harvest was initiated after a span of 4 weeks from inoculation. The nematode growth was less than expected at $0.9 \times 10^{6}$ due to decreasing moisture content and space.

The nematodes grown in modified dog-feed media was cultured with different concentration of feed source blended with sterile distilled water. The T1 flask containing nematodes had developmental changes in comparison to the nematodes in T4 flask. The nematodes in flask 4 had the highest number of IJs during harvest

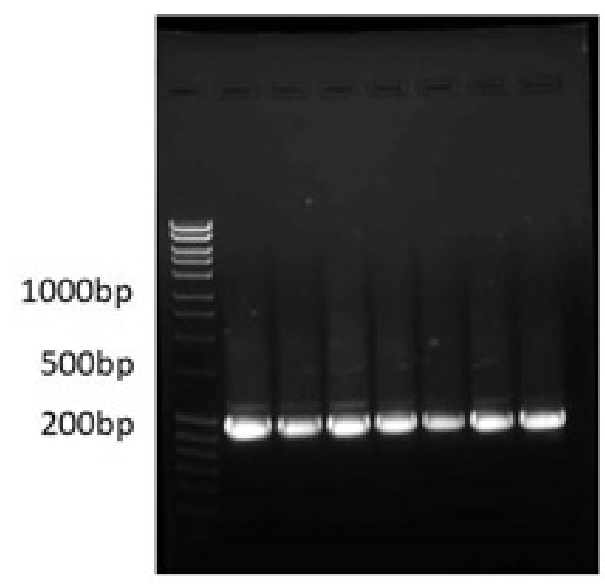

Fig.1a. PCR amplified products of isolated EPNs 


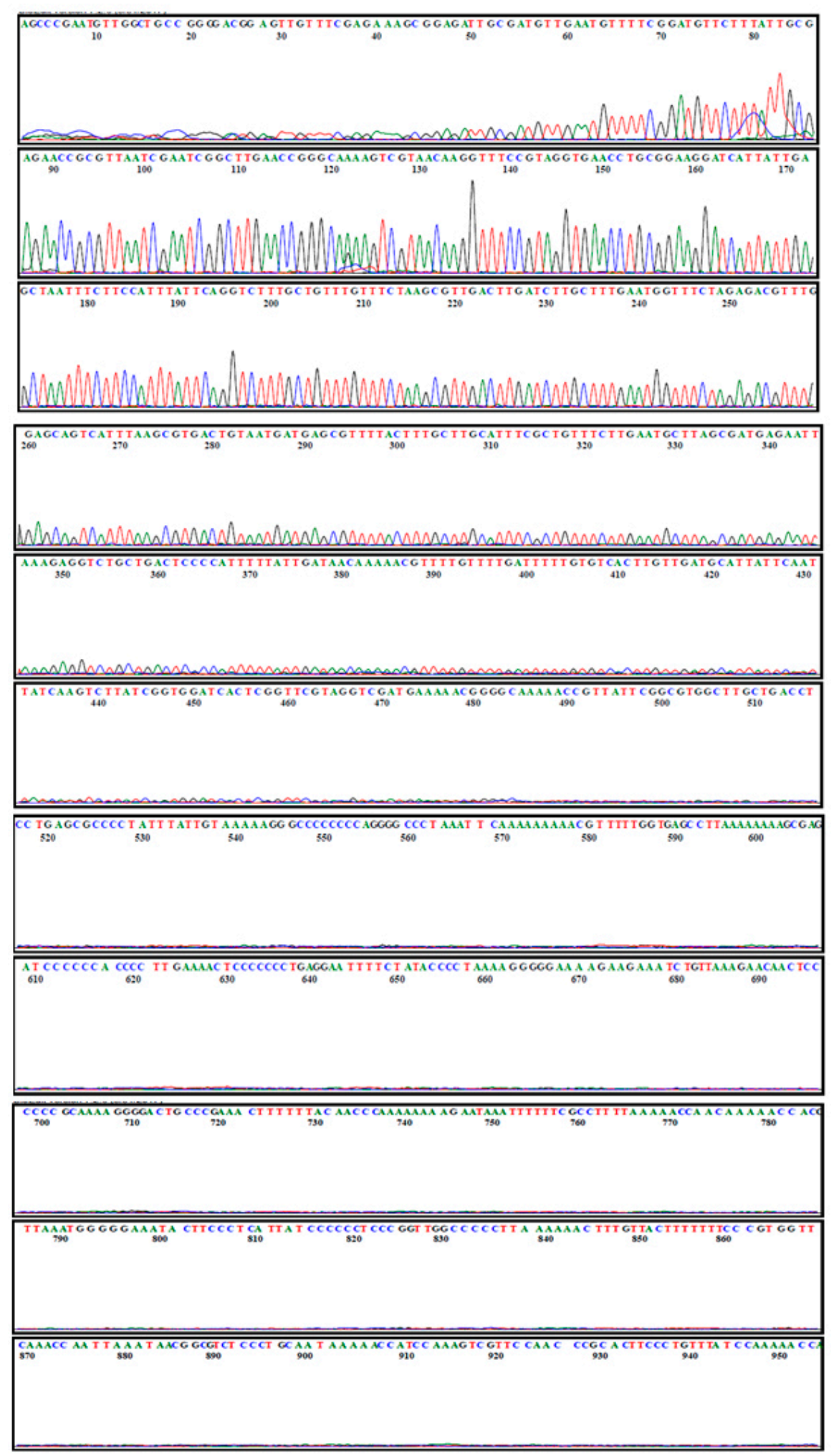

Fig. 1b. Chromatogram sequence analysis of Steinernema siamkayi KUT1 
from the T-flasks. Approximately similar number of nematodes was harvested from T flasks T1 and T2. The flasks with the lower food source like T3, $\mathrm{T} 4$ and T5 yielded very lesser quantity of IJs (Table $3 \& 4)$.

\section{DISCUSSION}

From the above results the entomopathogenic nematode was isolated from the cucumber soil for the Mass production. The Galleria melonella was used as the insect model for baiting the nematodes from the soil. The nematodes were collected and transferred from the insect host to solid In vitro media propagation (Wouts 1981). The 16SrRNA sequencing revealed the nematode strain as Steinernema siamkayai KUT1 and the symbiotic bacteria was identified as Xenorhabdus stockiae KUT6. For commercialisng the entomopathogenic nematode was finite due to the lack in the mass production of entomopathogenic nematode. Several research reports stated that the mass production of EPN in liquid media as biocontrol but the osmotic stress is also a major concern for bacterial phase I growth and nematode multiplication. Both these were affected due to change of bacterial growth to phase II variation (Ralf-Udo 2001). Nematode multiplication in liquid culture is a challenging method. The growth of nematode is based on various factors, the percentage of Dissolved

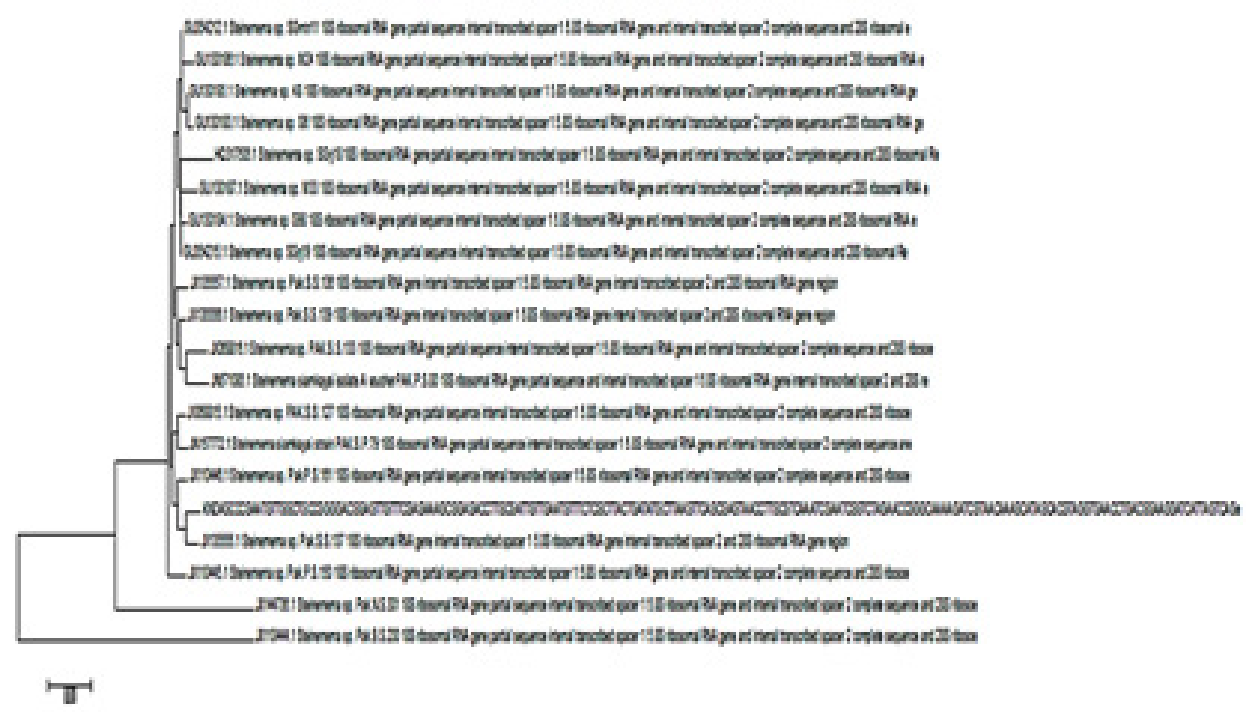

Fig. 2 Phylogenetic tree of Steinernema isolates found during the survey based on analysis of the ITS rDNA regions. The Phylogenetic analysis was performed by the neighbour-joining method with bootstrap analysis. Numbers indicated at the nodes represents bootstrap proportion values (50\% or more, 1000 replications)
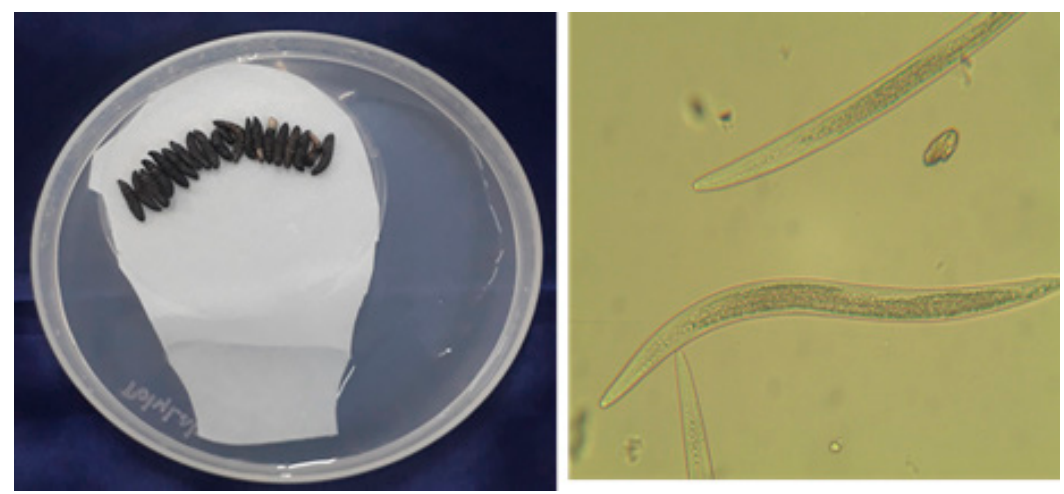

Fig. 3 Entomopathogenic Nematode infected Galleria mellonella and its morphological characterization of Steinernema saimkayai 


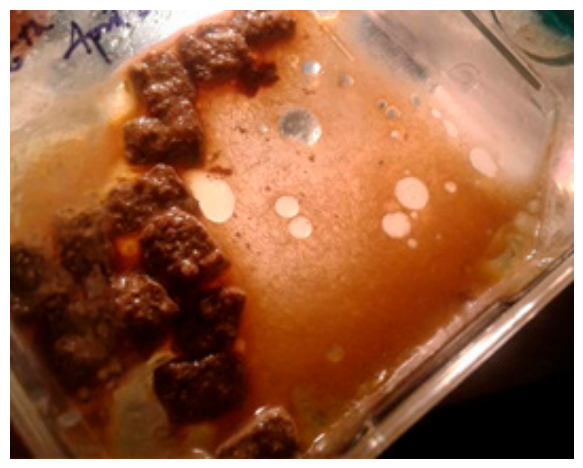

Fig. 4 Infective Juvenile in Semi solid Dog Feed Medium

oxygen in liquid medium. And the presence of toxic metabolites produced by the phase II shift of bacterial culture. Under stressed conditions, the bacterial culture reverses to phase II variation, which is detrimental to EPN multiplication (Samish et al., 2004). The morphometric characters of the Infective Juvenile Steinernema siamkayai KUT1 with Length $441 \mu \mathrm{m}$, Excretory pore $35 \mu \mathrm{m}$, and Tail Length $35 \mu \mathrm{m}$ was found to be similar with the early findings (Razia and Sivaramakrishnan 2014).

The mass production of Entomopathogenic nematode is important for plant protection, against malarial and dengue parasites. They are highly effective and surpass the harmful chemical compounds. In contrast to chemicals, which should not be displaced by water in the soil and have to decay within a few days, EPN are mobile and persistent. They recycle inside the host insect thus causing long-term, sustainable effects on the pest populations (Peters 1996). The use of EPN is safe for both the user and the environment. They have little detrimental effects on non-target insect populations and neither the nematodes nor their bacterial associates cause any detrimental effect to mammals or plants (Bathon 1996; Ehlers and Hokannen 1996). The commercial production of Entomopathogenic nematodes with Integated Pest Management are widely used against pests insects such as Fungus gnats in Mushrooms and Ornamentals; Cabbage root fly in Cabbage; March flies in Turf; House fly in Stables; Black vine weevil, Strawberry weevil in Strawberry, ornamentals, cranberry; Sugarbeet weevil in Sugarbeet; Citrus root weevil in Citrus; Peanut white grub in Sweet potatoes, peanuts; and also against Cutworms, Banana moth, Ghost moth, Cockroach, Mole cricket, Western flower thrips, Cat flea (Ralf-
Udo 2001). To control wider pest insects large amount of EPN is required but the production of EPN in liquid media is not capable of doubling the Steinernema siamkayai KUT1. Our research concludes the use of newly modified semi solid Dog feed medium can be safe and cheap enough for the mass production of EPN because of the presence of nutrients.

\section{CONCLUSION}

The EPNs are considered to be an effective biological control against Lepidopteran pests of important crops. Most of the nematodes have infective properties against major pests. From the soil EPNs were collected from the larva using White trap method. The nematodes collected were transferred to petri dishes and stored at $15^{\circ} \mathrm{C}$. Around 1000 Nematodes were used to check strain identification. The nematodes were surface sterilized and used as inoculum as for semi solid in vitro production of nematodes. Liquid formulation of media for nematodes resulted in poor growth of nematode. Bacterial culture due to its phase variation became a barrier in nematode development. Liquid formulations have to be optimized and symbiotic bacterial culture has to be stopped from moving towards phase II. In the newly modified semi solid dog feed medium, mass production of EPNs will be a tackle against crop pests.

\section{ACKNOWLEDGMENTS}

We would like to thank Department of Biotechnology, Karunya Institute of Technology and Sciences. Many thanks are extended to Dr. Sankaranaryanan Department of Nematology, Sugar Cane Breeding Institute. We thank Poomalai D for his timely help; and also acknowledging our thanks to Mathew C Abraham, Susan Mathew, Blesson Mathew for all the supports.

\section{CONFLICT OF INTEREST}

The authors declare that there is no conflict of interest.

\section{FUNDING}

This study was supported and funded by University Grant Commission - Maulana Azad National Fellowship (Grant Number - F117.1/2016-17/MANF-2015-17-KER-69816). 


\section{AUTHORS' CONTRIBUTIONS}

All authors listed have made a substantial, direct and intellectual contribution to the work, and approved it for publication.

\section{DATA AVAILABILITY}

All datasets generated or analyzed during this study are included in the manuscript.

\section{ETHICS STATEMENT}

This article does not contain any studies with human participants or animals performed by any of the authors.

\section{REFERENCES}

1. Agnello A, P Jentsch, E Shields, T Testa, and M Keller. Evaluation of Persistent Entomopathogenic Nematodes for Biological Control of Plum Curculio Art. NY Fruit, 2014; 22: 21-24.

2. Bathon H. Impact of entomopathogenic nematodes on Non-target hosts. Biocontrol Science and Technology, 1996; 6: 421-434. https://doi. org/10.1080/09583159631398

3. Ehlers R-U and HMT Hokkanen. Insect biocontrol with non-endemic entomopathogenic nematodes (Steinernema and Heterorhabditis spp.): conclusions and recommendations of a combined OECD and COST workshop on scientific and regulatory policy issues. Biocontrol Science and Technology; 1996; 6: 295-302. https://doi.org/10.1080/09583159631280

4. Gaugler JE, RL Kane, RA Kane and R Newcomer. Predictors of institutionalization in Latinos with dementia. Journal of Cross-Cultural Gerontology, 2006; 21: 139-155. https://doi.org/10.1007/s10823-0069029-8
5. Grewal PS, EE Lewis, R Gaugler and JF Campbell. Host finding behaviour as a predictor of foraging strategy of entomopathogenic nematodes. Parasitology, 1994a; 108: 207-15. https://doi.org/10.1017/ s003118200006830X

6. Hala MSM, MME Saleh, YA Mahmoud. Potential of the entomopathogenic nematode, Heterorhabditis marelatus, isolate in controlling the peach fruit fly, Bactrocera zonata (Saunders) (Diptera: Tiphritidae). Egyptian Journal of Biological Pest Control, 2018; 28: 22-29. https://doi.org/10.1186/s41938-018-0029-0

7. Joyce SA, AM Burnell and TO Powers. Characterization of Heterorhabditis isolates by PCR amplification of segments of mtDNA and rDNA genes. Journal of Nematology, 1994; 26:260-270.

8. Kaya HK and R Gaugler. Entomopathogenic nematodes. Ann. Rev. Entomology, 1993; 38: 181-206. https://doi.org/10.1146/annurev. en.38.010193.001145

9. Peters $A$. The natural host range of Steinernema and Heterorhabditis spp and their impact on insect populations. Biocontrol Science and Technology, 1996; 6: 389-402. https://doi.org/10.1080/09583159631361

10. Ralf-Udo E. Mass production of entomopathogenic nematodes for plant protection. Applied Microbiolgy and Biotechnology, 2001; 56: 623-633. https://doi. org/10.1007/s002530100711

11. Razia M and S Sivaramakrishnan. Isolation and Identification of Entomopathogenic Nematodes of Kodaikanal Hills of South India, 2014; 10: 693-699.

12. Samish M, H Ginsberg and I Glazer. Biological control of ticks. Parasitology, 2004; 129: 389-403. https://doi. org/10.1017/S0031182004005219

13. Seinhorst JW. On the killing, fixing and transferring to glycerin of nematodes. Nematologica, 1962; 8: 29-32. https://doi.org/10.1163/187529262X00981

14. Wouts WM. Mass production of the entomogenous nematode Heterorhabditis heliothidis (Nematode: Heterorhabditidae) on artificial media. Journal of Nematology, 1981; 13: 467-469. 